\author{
RESEARCH ARTICLE \\ 10.1029/2019JF005487 \\ Key Points: \\ - Multiyear UAV and seismic \\ monitoring yielded a catalogue \\ comprising timing, propagation, \\ and location of 81 coastal cliff \\ failures \\ - Failures are controlled by water \\ availability through subsurface \\ flow, rain, and atmospheric \\ moisture condensation \\ - Failures are controlled on diurnal, \\ monthly, seasonal, and multiyear \\ scales
}

Supporting Information:

- Supporting Information S1

Correspondence to:

M. Dietze,

mdietze@gfz-potsdam.de

Citation:

Dietze, M., Cook, K. L., Illien, L., Rach, O., Puffpaff, S., Stodian, I., \& Hovius, N. (2020). Impact of nested moisture cycles on coastal chalk cliff failure revealed by multiseasonal seismic and topographic surveys. Journal of Geophysical Research: Earth Surface, 125, e2019JF005487. https:// doi.org/10.1029/2019JF005487

Received 12 DEC 2019

Accepted 30 JUL 2020

Accepted article online 10 AUG 2020

(c)2020. The Authors.

This is an open access article under the terms of the Creative Commons Attribution License, which permits use, distribution and reproduction in any medium, provided the original work is properly cited.

\section{Impact of Nested Moisture Cycles on Coastal Chalk Cliff Failure Revealed by Multiseasonal Seismic and Topographic Surveys}

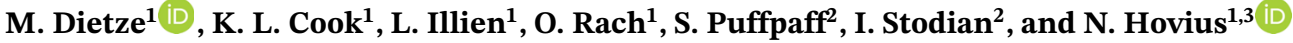 \\ ${ }^{1}$ Section 4.6 Geomorphology, GFZ German Research Centre for Geosciences, Potsdam, Germany, ${ }^{2}$ National Park \\ Authority Vorpommern, Research and Monitoring Division, Jasmund, Germany, ${ }^{3}$ Institute of Geosciences, University \\ of Potsdam, Potsdam, Germany
}

Abstract Cliff failure is a fundamental process shaping many coastlines worldwide. Improved insight into direct links between cliff failure and forcing mechanisms requires precise information on the timing of individual failures, which is difficult to obtain with conventional observation methods for longer stretches of coastline. Here we use seismic records and auxiliary data spanning 25 months to precisely identify and locate 81 failure events along the 8.6-km-long chalk cliff coast of Jasmund, on Germany's largest island, Rügen. The subminute precision of event timing allows the linkage of individual failures to triggers over a wide range of relevant time scales. We show that during the monitoring interval, marine processes were negligible as a trigger of cliff failure, although still being important for the removal of resulting deposits. Instead, cliff failure was associated with terrestrial controls on rock moisture. Most failures occurred when water caused a state transition of the cliff forming chalk, from solid to liquid. Water content was modulated by (i) subsurface flow toward the cliff, (ii) rain onto the cliff, and (iii) condensation of atmospheric moisture, leading to clustered failures preferentially during the night. Seasonal water availability, controlled by plant activity, imposed an annual cycle of cliff failure, and wetter and drier than average years imposed a month-long legacy effect on cliff failure dynamics. Similar terrestrial control mechanisms may also be relevant for other coastal chalk cliffs, in addition to already investigated marine triggers.

Plain Language Summary Cliffs line many coastlines worldwide. They are eroded by cliff falls, with consequences for human safety, land loss, ecosystem dynamics, and availability of sediment along the coast. The discrepancy between rapid, short-lived failure processes and episodic observation techniques does not allow for a full analysis of the causes and drivers of cliff erosion. Combining measurements from a seismometer network on Germany's largest island, Rügen, with 3-D models from drone surveys and weather station data, we detected, located, and timed 81 cliff failures in 2 years and analyzed the circumstances that gave rise to their occurrence. These events were predominantly associated with the presence of water, which turns the solid, cliff-building chalk into a failure-prone slurry. Water availability is modulated at different time scales by rain on the cliff and moisture condensation, soil water flow, vegetation water uptake, and possibly the lunar cycle. Our findings sharpen the picture of when and why cliffs fail and offer a better prediction of the impact of global change on cliff coasts.

\section{Introduction}

Coastlines host about $40 \%$ of the world's global population along with key infrastructure, cultural heritage, and unique ecosystems (Menatschi et al., 2018). Coastal change can have a profound impact on these assets. Around half of the world's coasts consist of eroding cliffs (Young \& Carilli, 2019). On these coasts, cliff failure occurs across a range of scales and by a multitude of processes acting on the different materials that form cliffs (e.g., Collins \& Sitar, 2008; Duperret et al., 2005; Kogure et al., 2006; Rosser et al., 2013; Stephensen, 2014). A fundamental mechanism of coastal retreat worldwide, cliff failure is driven by cyclic loading and activation due to climate-driven processes. After a preparation phase, during which a cliff section is driven to instability, for example, by weathering, propagation of discontinuities, undermining at the cliff base, or simply by static loading (Duperret et al., 2005; Kogure et al., 2006), failures can be initiated by a variety of trigger mechanisms. These include impact of tide- and storm-driven waves that exert forces on the cliff, entrain abrasive sediment, and change the cliff geometry, for example, through undermining 
(Collins \& Sitar, 2008; Stephensen, 2014), wind-induced stress (Vann Jones et al., 2015) amplified when interacting with trees (Dietze, Turowski, et al., 2017), frost shattering or ice segregation and freeze-thaw cycles (Letortu et al., 2015), and rainfall and groundwater recharge causing gravitational loading and reduced shear strength due to increased pore water pressure (Stephensen, 2014). In addition, failures can cause further failures, leading to upward propagation of cliff erosion with time (Rosser et al., 2013). Finally, there may also be failures that appear to happen without any clearly attributable trigger mechanism, or with a trigger that a study design has not accounted for.

Robust attribution of cliff failure to a particular triggering process depends on precise knowledge of the timing and location of the event, and of the preceding and concurrent conditions. Cliff failure is generally a rapid process once initiated, and relevant conditions can change on short time scales (minutes to days). Therefore, especially for large failures, triggers can remain difficult to identify or to link with the actual process (Collins \& Sitar, 2008; Rosser et al., 2013). Many past studies have used records of cliff failure with monthly or coarser time resolution (e.g., Lim et al., 2010; Vann Jones et al., 2015). While these studies have yielded valuable insights, data with hourly or better resolution may help to robustly constrain causal links. In this context, environmental seismology offers a useful approach, because of its ability to deliver both high time resolution (at least subminute) and scalable location precision (usually $5-10 \%$ of the interstation distance) for individual cliff failures.

Networks of seismic sensors can be used to detect, locate, and estimate the volume and anatomy of mass movements at the landscape scale (e.g., Burtin et al., 2016; Helmstetter \& Garambois, 2010; Hibert et al., 2011). The size limit of detection with a network with a given station spacing and instrument configuration is set by the ambient noise level and depends on the transfer of energy from a mass movement into the substrate, as well as on ground properties that determine the propagation and attenuation of the resulting seismic waves. Dietze, Mohadjer, et al. (2017) were able to seismically detect rockfall volumes as small as $0.05 \mathrm{~m}^{3}$ with a fall height of less than $50 \mathrm{~m}$ and to locate them with deviations from independently constrained positions of about $80 \mathrm{~m}$ on average ( $7 \%$ of the mean station spacing). This means that while discrete, failure-based erosional fluxes can be tackled by the seismic approach, the diffuse part of an erosional budget remains elusive. The main strength of this approach, however, is the continuous temporal coverage of a larger area and precise time information for the onset and duration of discrete events. The high temporal resolution of seismic data is a key to identifying sensible triggers of failures by systematically measuring time lags between potential triggers and recorded geomorphic processes (e.g., Dietze, Turowski, et al., 2017).

In this study we explore the drivers and triggers of coastal cliff failures on the Jasmund peninsula, part of Germany's largest island, Rügen. We use seismic and unmanned aerial vehicle (UAV) monitoring to detect, date, locate, verify, and quantify cliff failures over a period of 2 years. We analyze the spatial and temporal patterns of cliff failure in the context of marine, meteorological, biological, and hydrological boundary conditions across scales from minutes to years. This yields quantitative constraints on the relevance of triggers and drivers at distinct time scales.

\section{Materials and Methods}

\subsection{Study Site and Instrumentation}

The study area on the Jasmund peninsula of Rügen comprises an iconic cliff coast section with a length of $8.6 \mathrm{~km}$. The cliffs are steep $\left(57_{-4}^{+8 \circ}\right.$, median and quartiles-used here and throughout to account for nonnormally distributed data) to partly overhanging and up to $118 \mathrm{~m}$ high $\left(48_{-13}^{+13} \mathrm{~m}\right)$. They are facing the Baltic Sea to the northeast, a semienclosed basin with a minimal tidal range (about $15 \mathrm{~cm}$; IZW, 2003). Located in a National Park, the area has been covered by a beech forest for more than 1,000 years. The local weather is dominated by an oceanic regime (DWD, 2019), with less than $5^{\circ} \mathrm{C}$ diurnal air temperature range, positive mean monthly air temperatures throughout the year $\left(7.9^{\circ} \mathrm{C}\right.$ annual average, ranging between $0.2^{\circ} \mathrm{C}$ and $16.5^{\circ} \mathrm{C}$ ) and $286-\mathrm{mm}$ precipitation during summer (defined in this study between May and October) versus $236 \mathrm{~mm}$ during winter (defined here between November and April), resulting in 522-mm annual average, and ranging between 27 and $60 \mathrm{~mm} / \mathrm{month}$. Access to this area is limited and restricted to the existing trails, and a human role in triggering cliff failure in the area can mostly be excluded.

The Jasmund cliffs have formed in weakly cemented Maastrichtian chalk, which has been folded and thrusted by the Scandinavian ice sheet into a sequence of stacked blocks and covered by till (Gehrmann, 2018). Water content has an important effect on the stability of chalk in general and chalk cliffs 
(a)

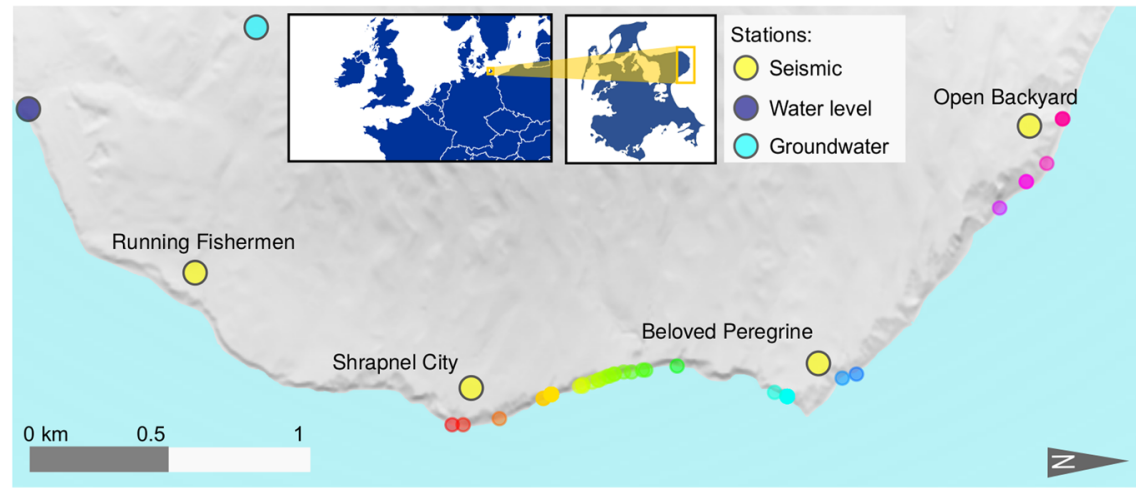

(b)

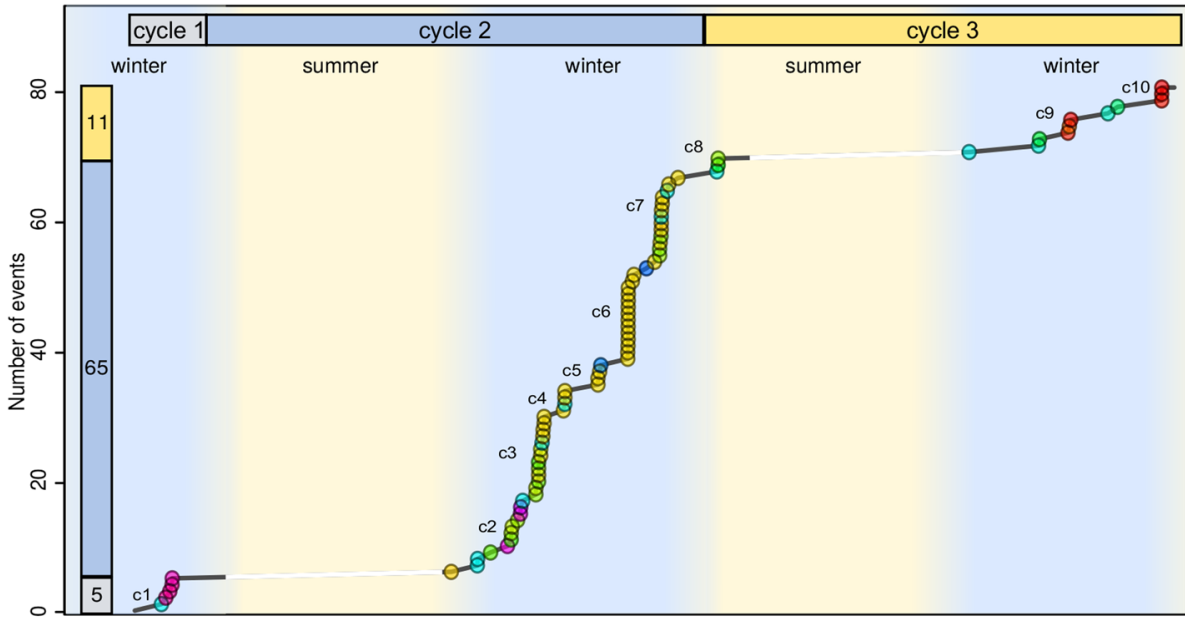

(c)

(d)
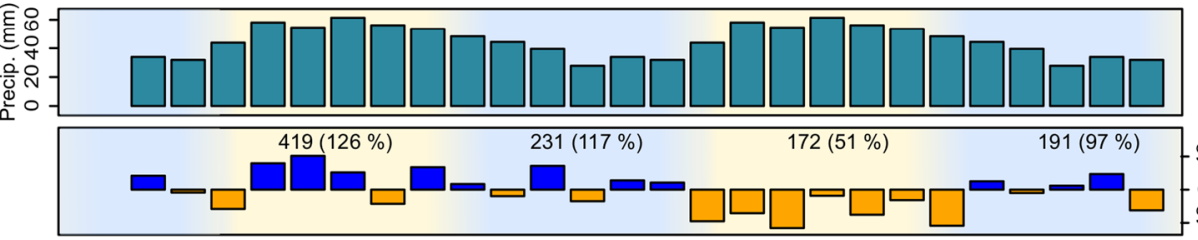

(e)

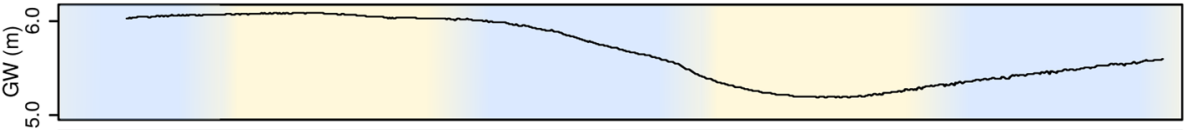

(f)

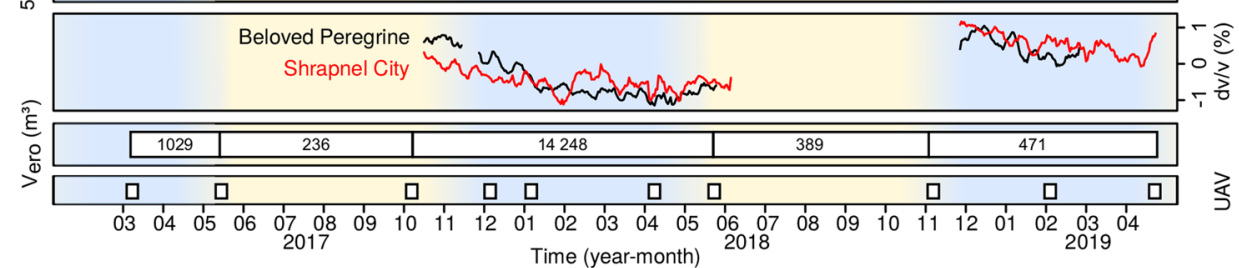

Figure 1. Study area and data sets. (a) Hillshade map of study area with seismically detected failures (colored by location). (b) Failures with numbered event clusters. Vertical and horizontal bars denote seasonal cycles with cumulative number of failures per cycle. Circle color corresponds to locations in (a). White line sections depict periods without seismic data coverage. (c) Monthly 30-year average precipitation sums (DWD, 2019). (d) Precipitation deviations from monthly averages. Numbers denote precipitation sums per season, indicated by yellow and blue background colors. Values in parentheses denote relative deviations from 30-year averages. (e) Groundwater level (STALUVP, 2019) above $108 \mathrm{~m}$ asl. (f) Seismic wave velocity changes (dv/v). (g) UAV-based failure volume sums per season. (h) UAV flight dates. 
in particular (Duperret et al., 2005; Obst \& Schütze, 2005; Voake et al., 2019). The plasticity index $\left(I_{p}\right)$, a classic measure of rigidity in engineering geology (Williams, 2016), of the chalk bedrock of our study area is $7.8 \pm 1.2$ (C. Koepke, BAUGRUND Stralsund engineering office, 16 May 2019, personal communication). This suggests that water content changes of less than $10 \%$ can have fundamental effects on the state of the rock mass. In Rügen chalk, the transition from rigid to semirigid occurs at $22.0 \pm 2.0 \%$ and the transition to liquid at $29.8 \pm 2.5 \%$ water content. The average water content of Rügen chalk is around 23\% (LUNG, 2019). Hence, the cliff material is likely mostly in a metastable state, and wetting and drying cycles may cause frequent transitions between rigid, semirigid, and liquid states. These material properties are consistent with more detailed studies from northwest France, where chalk also forms sea facing cliffs. Duperret et al. (2005) found minimum natural water contents between $9.6 \%$ and $27 \%$ (19\% on average) and measured strength reductions of $40-50 \%$ when fresh water was added to the chalk, and $52-73 \%$ strength reductions for sea water uptake.

The Jasmund cliffs have retreated by erosion at about $25 \mathrm{~cm} /$ year on average, generating a cumulative annual total of 103,000 $\mathrm{m}^{3}$ of debris along the coast section (Obst \& Schütze, 2005). This erosion estimate is based on Holocene time scale evidence and allows for significant short-term variability. We note a similarity with rates of $25 \mathrm{~cm} /$ year for other regions with comparable cliff forming rocks, such as in northwest France (Duperret et al., 2005), despite important differences in the wave and tidal energy of these coasts.

Between March 2017 and April 2019, we operated four seismic stations (Nanometrics Trillium Compact 120-s seismometers and PE6/B 4.5-Hz geophones, logged at $200 \mathrm{~Hz}$ by Digos DataCubes), at intervals of about $1.2 \mathrm{~km}$ along $7 \mathrm{~km}$ of the Jasmund cliff coast. The sensors were deployed in $50 \mathrm{~cm}$ deep, hand dug pits, directly installed in the outcropping chalk or till deposits, and mantled with fine sediment filled back into the pit. Data loggers and $72 \mathrm{Ah}$ lead batteries were kept in water proof plastic boxes, also placed in hand dug pits about $50 \mathrm{~cm}$ next to the sensor, with only the GPS antenna looking out to safeguard time stamp availability for the data. The system was able to operate for about 3 months without data extraction and battery replacement maintenance visits. Instrumentation was active during the autumn to late spring season, and the sensors were dismantled during the summer period.

Repeat UAV surveys were used to generate high-resolution 3-D point clouds to quantify topographic changes. These change data sets were used to verify seismic failure detections and locations, to provide precise locations along the cliff, detachment heights above the shore line and below the cliff top, and to estimate the volumes of failed material. In addition, we used the UAV data to quantify failure volumes during the summer periods, for which no seismic data were available. Surveys (Figure $1 \mathrm{~h}$ ) were performed using consumer-grade DJI UAVs, including a Phantom 3 Advanced (March 2017, May 2017, and December 2017), a Mavic Pro (October 2017, January 2018, April 2018, and May 2018), and a Mavic 2 Pro (November 2018, February 2019, and April 2019). Each survey consisted of multiple flights from up to seven locations along the cliff, yielding 1,000-2,000 photos for a full survey. The December 2017, January 2018, and April 2018 surveys were partial surveys, covering the most active cliff sections between and about $500 \mathrm{~m}$ beyond the two central seismic stations. The UAVs were flown manually and set to take photographs every $3 \mathrm{~s}$. For a given survey, each section of the cliff was covered by at least two passes of the UAV with different flight elevation and camera obliquity. Camera angles typically ranged from $40-80^{\circ}$ from nadir, and elevations from 30-150 $\mathrm{m}$ above sea level. The distance between the camera and cliff varied depending on cliff height and weather conditions.

In addition to the seismic and UAV information, we used weather data at hourly resolution from the Arkona station of the Deutscher Wetterdienst, $20 \mathrm{~km}$ to the northwest (DWD, 2019), sea level data with minute resolution (WSV, 2019) from a gauge at the southeast limit of the study area in Sassnitz (Figure 1a), and daily groundwater data (STALUVP, 2019) from a well in chalk material $1.5 \mathrm{~km}$ west of the cliff coast (Figure 1a). For subsequent analyses (see section 4.3), we also used the HORIZONS web interface (JPL, 2019) to retrieve hourly lunar Ephemerides (data of the distance between the study area and the Moon's center of gravity).

\subsection{Data Processing}

Seismic data were processed with the R package “eseis” v. 0.5.0 (Dietze, 2018a, 2018b). Typical seismic waveforms of gravitational mass wasting events are spindle shaped (Hibert et al., 2011) and registered at seismic stations with a few seconds offset across our local network due to the finite velocity with which the seismic waves travel through the ground (Figure 2f). To identify these discrete events in the continuous stream 
(a)

(b)
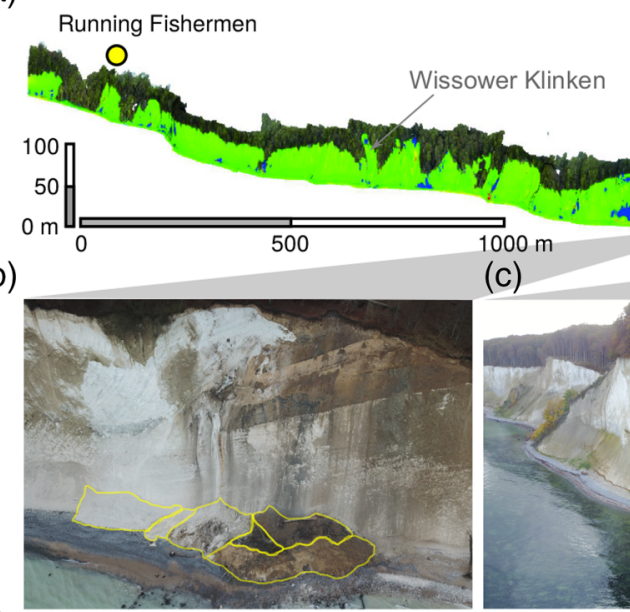

(f)

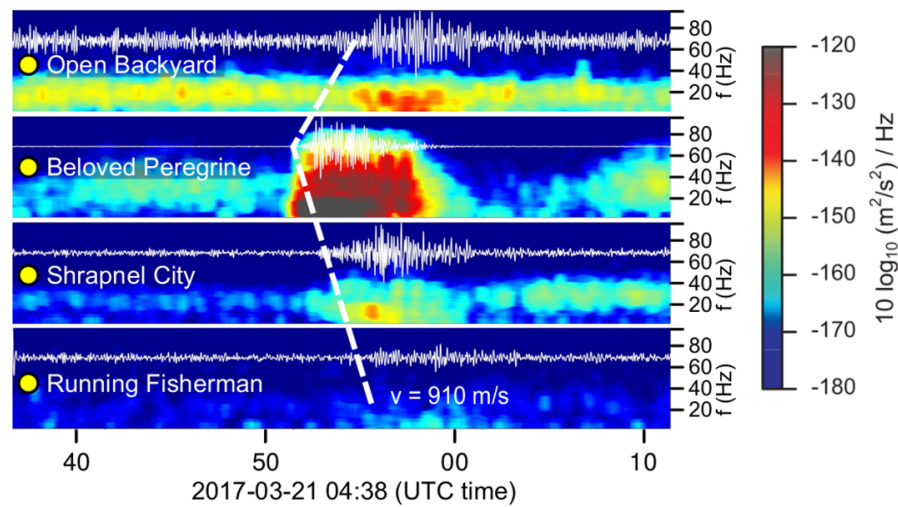

(c)

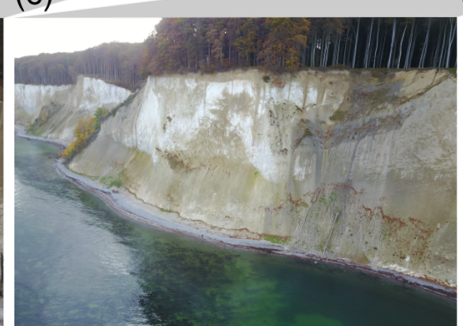

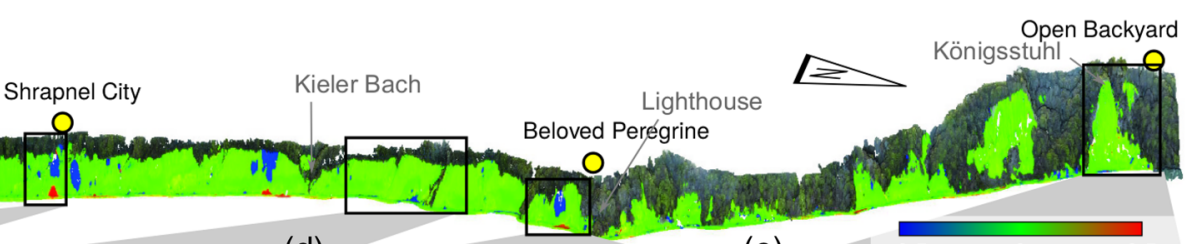

(d)

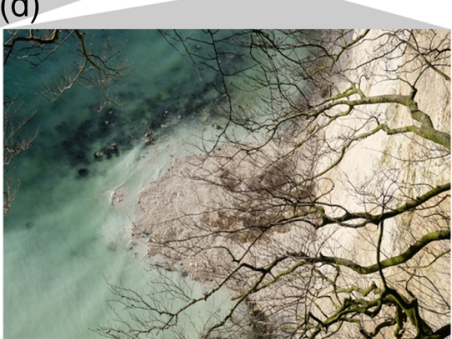

(e)

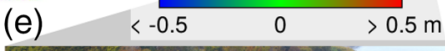

(g)

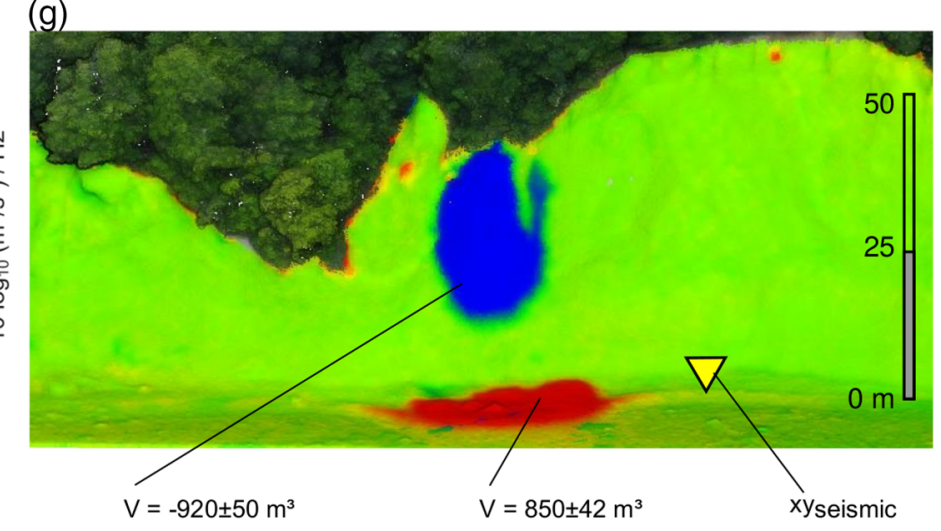

Figure 2. Cliff failure locations, anatomy, and deposits. (a) UAV-based cliff activity for the entire study period, shown as perspective oblique view from the sea. Tree carapace is shown in natural dark green color. Color bar indicates surface change in meters. (b) Site that exhibited repeated failure activity with discrete subdeposits (yellow polygons), below station "Shrapnel City." (c) Perspective view along the cliff toward the south with sequence of stacked chalk units. (d) Terrestrial picture of recently failed site close to station "Beloved Peregrine." Note the suspension plume originating from failure deposit as direct consequence of waves incising the material reaching beyond the beach zone. (e) The Königsstuhl, highest part of the cliff section under survey. (f) Failure from (d) as recorded by the seismic stations with an apparent wave velocity of $910 \mathrm{~m} / \mathrm{s}$. The $5-10 \mathrm{~Hz}$ filtered signals with their spindle-shaped evolution in time are plotted on top of spectrograms. (g) UAV-based volume changes for the failure in (d), based on UAV data from March and May 2017; perspective from the sea. Yellow triangle depicts best match seismic location, about $37 \mathrm{~m}$ north of the UAV-based location. For enlarged versions of photos in (b)-(e) see the SI.

of seismic data, we used a STA-LTA picker (Allen, 1982). For details on the settings and parameter constraints, see the supporting information (SI). We screened these events with a series of automatic rejection criteria, admitting only those that lasted between 1 and $180 \mathrm{~s}$ (assuming that shorter cases are random signal coincidences and longer signals are caused by earthquakes or anthropogenic activity). We considered only events detected by at least three seismic stations (minimum required to locate an event), within $11 \mathrm{~s}$ (maximum time required for a seismic signal to travel through the network). All admitted events were manually checked for plausibility based on (i) consistent amplitude decrease across the network as expected for a local seismic source; (ii) consistent signal arrival time delay across the network, indicative of a local source predominantly emitting surface waves; (iii) an emergent onset and slow decay of the signal, as reported for many hillslope mass wasting processes (Dietze, Mohadjer, et al., 2017; Helmstetter \& Garambois, 2010; Hibert et al., 2011); (iv) absence of earthquake-like distinct arrivals of different wave types; and (v) absence of tremor-like frequency patterns, often associated with overhead passage of aircraft (Meng \& Ben-Zion, 2018).

Detected events that passed manual screening were located by migration of the deconvolved, filtered vertical component signal envelopes (Burtin et al., 2013; Dietze, Mohadjer, et al., 2017). The final location estimates are reported as projections along the coast. This is done only for failures whose $90 \%$ confidence interval overlapped with the coast, which is the only likely area of active mass wasting in the otherwise gently undulating landscape. The migration approach requires an assumed seismic wave velocity. Here, we used an example 
failure (Figure 2f) for which we know the location independently, and minimized the deviation of the seismic location estimate from the known location. Migration results also depend on the window with which the seismic data were filtered. Therefore, we have also tested the location deviation as a function of filter width. For this, we ran the optimization routine for different filter windows, keeping the lower corner frequency constant at $5 \mathrm{~Hz}$ and gradually increasing the higher corner frequency from 6 to $20 \mathrm{~Hz}$. All detailed processing steps are described in the SI, including annotated R scripts.

Seismic wave velocities vary in time, as the mechanical properties and water content of their medium change (Larose et al., 2015). Seismic noise cross correlation analysis can be used to infer changes in the relative seismic wave velocity (dv/v) and thereby to monitor the properties of the local substrate (Snieder, 2004). We determined dv/v for the two central stations ("Beloved Peregrine" and "Shrapnel City," all named after specific deployment characteristics) with the MIIC package (Sens-Schönfelder, 2014). Hourly signals were processed by filtering $(4-8 \mathrm{~Hz}$ ), spectral whitening, clipping at two standard deviations and sign normalization, and the cross-correlation functions were stacked to daily data. These results were converted to $\mathrm{dv} / \mathrm{v}$ values using the stretching technique of Sens-Schönfelder and Wegler (2006). For mathematical background see the SI.

UAV data processing was done using Agisoft Photoscan (v. 1.4.2) structure from motion (SfM) software. The cliff was split into five overlapping segments in order to reduce processing time. We were unable to deploy or measure ground control points for the cliff surveys because of the National Park status of the study area, the inherent danger of failures preventing us from accessing the beach, and dense vegetation cover and danger of failure of the overhanging top parts of the cliff. Thus, the surveys were georeferenced using only the GPS data recorded by the UAVs. In order to obtain reliable change detection results, we followed the co-alignment workflow introduced in Cook and Dietze (2019). For each pair of surveys that were compared, we combined photos from both surveys for point matching, initial bundle adjustment, and optimization (following removal of tie points with reconstruction uncertainty ratio $>50$ ). The two sets of photos were then separated for the dense cloud construction. Parameters for alignment were high-quality, key point limit of 40,000 , tie point limit of 4000 , and adaptive camera model fitting. Parameters for dense cloud construction were medium quality and aggressive depth filtering. The dense point clouds were compared using the $\mathrm{M} 3 \mathrm{C} 2$ algorithm (Lague \& Leroux, 2013) in CloudCompare (GPL, 2019) using the parameters: core point spacing $0.25 \mathrm{~m}$, projection diameter $0.5 \mathrm{~m}$, and normal scales 0.5 to $4.5 \mathrm{~m}$ in $1-\mathrm{m}$ steps. The accuracy of the resulting change cloud was assessed using the calculated changes in the stable areas of the cliff (typically the majority of the cliff face). We estimate a level of detection of $10-15 \mathrm{~cm}$ or better for our change maps.

We manually inspected each of the change maps in concert with the available before and after photographs to identify cliff failures. For each identified failure, we clipped the before and after point clouds to the area of measured change and calculated the volume using the $2.5-\mathrm{D}$ volume tool in CloudCompare. We calculated each volume three times using the $X, Y$, and $Z$ reference planes to determine the most appropriate reference plane for a given failure and estimate a relative volume uncertainty ( $9.7 \%$ on average). In addition, we estimated the elevation of the center of each failure to give the height above the shoreline and the vertical distance from the cliff top.

\subsection{Estimation of Seismic Detection Limit}

A cliff failure will only be detected when it emits sufficient kinetic energy to the ground. Since we need such a signal to be recorded by at least three seismic stations to locate the seismic source, the energy must be large enough to allow signal propagation over at least twice the average seismic station distance (1.2 km). On 26 January 2019 National Park staff cut trees along the main road crossing the forest. The felling sites were between 2.0 and $2.5 \mathrm{~km}$ away from the closest three seismic stations of our coastal array. Forest staff confirmed that the largest trees had masses of up to $10 \mathrm{t}$ and heights of up to $30 \mathrm{~m}$. During this felling period, we had a further seismic station ("Fairground Attraction") running in the study area, located $1.7 \mathrm{~km}$ northwest of the station "Shrapnel City," recording with the same instruments and parameters as the other stations (Figure 3). We screened the seismic records of all stations during the tree felling to obtain conservative estimates of the minimum detectable volume of chalk material failing along the cliff. Therefore, we assume that maximum energy can be delivered to the ground if a tree would fall without any internal absorption of energy by swaying and bending branches and treat a tree fall as free fall process of the entire tree mass from the mean tree height. 
(a)

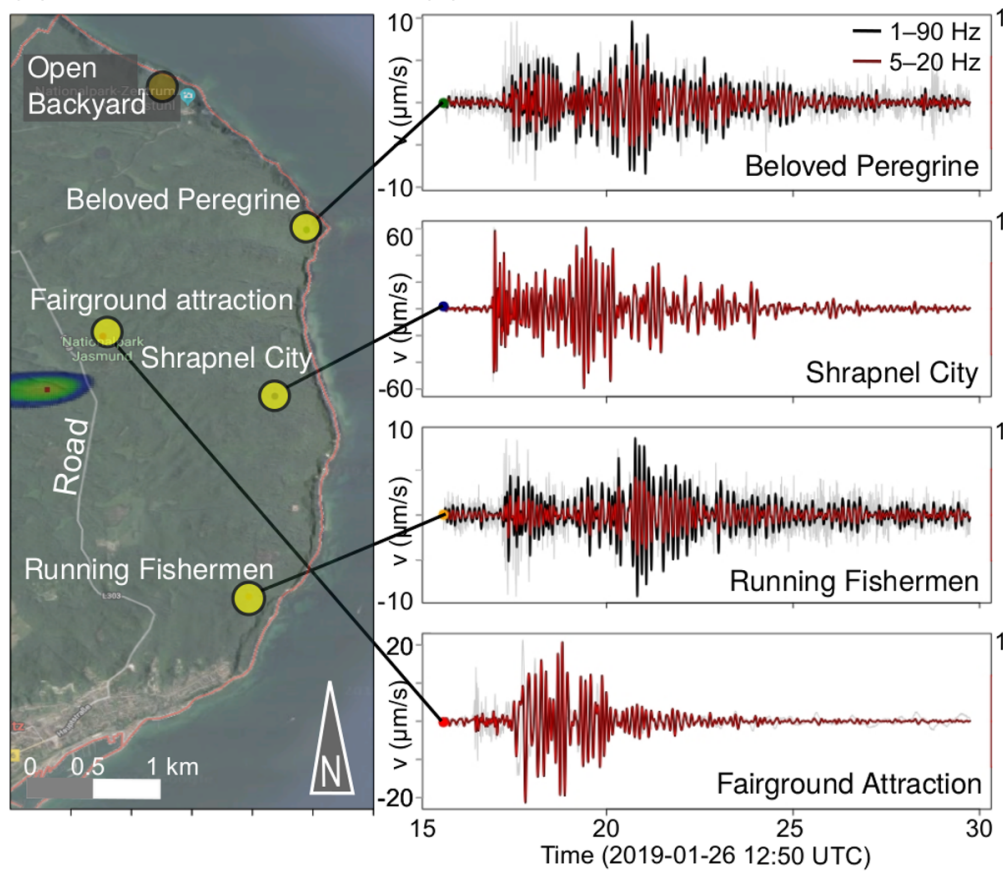

(c)

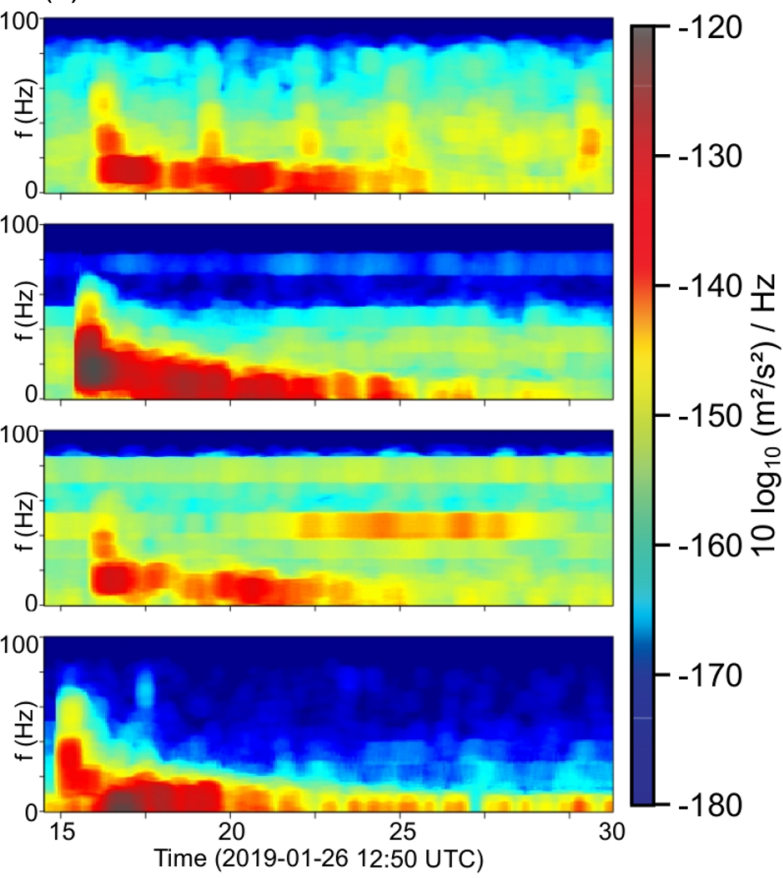

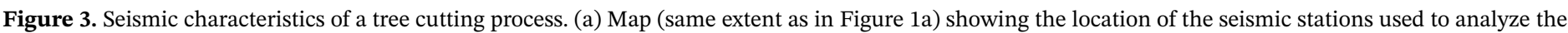

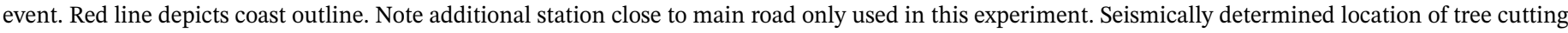
event is shown as colored polygon with center 100 west of the road, where the tree was actually cut. (b) Seismic signals of the event at two different filter windows (black and red lines) and as unfiltered seismograms (gray lines). (c) Seismic spectrograms of the signals.

We were able to detect a series of at least 15 seismic signals (see Figure 3 for an example). The signal amplitudes were always recorded well above background noise levels at all operating stations, by a factor of 5 to 30 , and the sources were, in many cases, located along the road where the trees were being cut. In the extreme case, a 10-t tree (based on the estimates of National Park staff and a specific density of the wood of about $1,000 \mathrm{~kg} / \mathrm{m}^{3}$ ), falling freely from an altitude of $15 \mathrm{~m}$ (half the stem height), and without impact damping by branches, litter, or loose soil, generated a seismic signal that can be detected by stations of our seismic array at a distance of at least $2.5 \mathrm{~km}$. Such a mass would correspond to a chalk volume of $4 \mathrm{~m}^{3}$ falling from a height of $15 \mathrm{~m}$, given a density of chalk of $2,500 \mathrm{~kg} / \mathrm{m}^{3}$. The distance between our stations and the monitored cliff section is considerably smaller, and the true limit of systematic detection is thus likely lower.

\subsection{Trigger Analysis}

A wide range of triggers may cause rock slope failure. From this range we can exclude geophysical (earthquake and volcanic eruption; Hibert et al., 2014) and other gravitational processes (snow avalanches, ice falls, and debris flows; Stock et al., 2013) due to the location of the study site. Biological or anthropogenic triggers (animal traffic and human activities; Wieczorek, 1996) are unlikely in a protected area with virtually no access to the cliff face or any macrofauna activity along it. Thermal dilation and contraction (Collins \& Stock, 2016; Stock et al., 2013) are assumed to play a subordinate role in generating stress cycles within the rock mass, given that the northeast facing aspect of the cliff prevents intense and prolonged exposure to direct sunlight, especially during winter time. The daily amplitude of air temperature was $3.7_{-1.1}^{+1.3{ }^{\circ} \mathrm{C} \text { for }}$ the entire study period, with even lower amplitudes during the November-May period $\left(3.1_{-0.9}^{+1.3 \circ} \mathrm{C}\right)$. Since the propagation of temperature changes into the ground is associated with significant attenuation of the amplitude within a few centimeters (e.g., Holmes et al., 2008), and mechanical tests of the temperature effect on the tensile strength of chalk (e.g., Voake et al., 2019) showed only minimal effects compared to the impact of wetting, we consider it unlikely that such small air temperature amplitudes play a primary role in affecting the chalk material properties. Similarly, the tidal range of the Baltic Sea is about $15 \mathrm{~cm}$, equivalent to the diameter of larger sediment clasts on the beach at the foot of the cliff. Moreover, in many places the beach forms a ramp of 2-m height from the water line to the cliff base. Thus, we consider tidal effects unlikely to be a dominant process affecting cliff failure. 
Geotechnical measurements suggest that, under normal conditions, the chalk rock mass of the Jasmund peninsula may be close to or beyond a transitional state (rigid to semirigid or even liquid), and addition of comparatively small amounts of water may have significant effects on the stability of landforms built by this material. With the concept of a system sensitive to water content in mind, we focused our exploration for likely triggers of cliff failure on precipitation, wind, freeze-thaw transitions, sea level, and wave action (Dietze, Turowski, et al., 2017; Kennedy et al., 2017).

We assessed the relevance of these trigger types by analysis of the time difference between a failure and the preceding trigger occurrence (Dietze, Turowski, et al., 2017). This assumes that a geomorphic response occurs while a trigger is active or after it has been active, either without delay or with a trigger-specific time lag (cf. Dietze, Turowski, et al., 2017, for detailed discussion of expected time lags). The resolution of any trigger analysis is limited by the resolution of both event timing and trigger proxy data. With our seismic detection methods, we are able to achieve at least subminute resolution of event timing, rendering trigger proxy timing $(<1 \mathrm{hr})$ the limiting factor.

To evaluate the role of precipitation in triggering of cliff failures, we calculated time lags with rain fall of $0.1 \mathrm{~mm} / \mathrm{hr}$ (the smallest measurement increment), $0.2 \mathrm{~mm} / \mathrm{hr}$ (quantile ${ }_{0.05}$ of the range of recorded rain intensities), and $0.5 \mathrm{~mm} / \mathrm{hr}$ (quantile ${ }_{0.10}$ ). Further, thresholds could be included but would most likely result in systematically changing time lags as during rain storms the rain intensity is temporally autocorrelated. For wind, we defined wind events as episodes with 1-hr average wind speeds at Beaufort scale 6, labeled "strong wind," or higher. Freeze-thaw episodes were defined as transitions from negative to positive Celsius near-ground air temperatures, acknowledging that heat dissipation into the ground can take several hours (Dietze, Turowski, et al., 2017) and that there may be differences in air temperature between the study site and the meteorological station. The role of sea level as a direct trigger of cliff failures (i.e., minimal time lags) was assessed by calculating time lags for levels corresponding to the quantiles ${ }_{0.75,0.90,0.95}$ of the full distribution of sea level data (i.e., 16, 26, and $33 \mathrm{~cm}$ above average sea level, respectively). In the absence of wave buoy data, we cannot directly constrain wave height. Thus, we calculated the standard deviation of sea level in a moving window of $20 \mathrm{~min}$, assuming that during storms higher wave amplitudes will result in greater standard deviation values (i.e., increased variability of sea level around the mean).

The time lags for all triggers are visualized as kernel density plots, which provide a continuous representation of the empirical density distribution of the data, and are similar to histograms but without the bias created by definitions of bin sizes and class boundaries (Dietze et al., 2016). We restricted the analysis to a maximum time lag of $72 \mathrm{hr}$, assuming that all triggers operate at time scales shorter than 3 days. To estimate the significance of our analyses, we tested the time lag distributions resulting from the empirical failure catalogue for statistical difference from 1,001 synthetic event data sets of the same size as the empirical catalogue. Each synthetic data set was generated by randomly assigning start times for the entire study period. We used the two-sample Kolmogorov-Smirnov (KS) test to evaluate whether the distributions are significantly different from random occurrence or not.

Although we do not have the same temporal resolution data between winter and summer for cliff collapse identification, the length of the monitoring period (25 months) allows us not only to investigate time lags to triggers but also to identify activity variations across time scales from diurnal to lunar orbital and annual. For these cycles we calculated spectra of the continuous time series of potential triggers and drivers. The discrete distribution of cliff failures was converted to a continuous distribution by calculating a kernel density estimate with hourly resolution and a window size of 2 days, and normalizing the resulting density values.

\section{Results}

\subsection{Event Detection, Location, and Anatomy}

Automatic picking of seismic events yielded a total of 2,818 potential cliff failures. After manual screening and validating that seismic locations were along the coast, we confirmed 81 as likely actual cliff failures (Figure 1). The 81 seismically detected failures (figures in SI A5) lasted in general $9.0_{-2.0}^{+2.9} \mathrm{~s}$, almost exclusively with an emergent onset, signal rise times (time from signal onset to maximum amplitude) of $2.8_{-0.8}^{+1.5} \mathrm{~s}$, and fall times (time from maximum amplitude to event end) of $6.7_{-2.0}^{+2.0} \mathrm{~s}$. The signals had central frequencies of $15.9_{-4.2}^{+6.6} \mathrm{~Hz}$. In $26 \%$ of all cases, a failure was followed by at least one other event less than $200 \mathrm{~m}$ away within $24 \mathrm{hr}$. We recorded one event cluster composed of 11 discrete failures during $10.5 \mathrm{hr}$, starting on $9 \mathrm{March}$ 2018 16:17:15 UTC (see SI Table S3). 
(a)

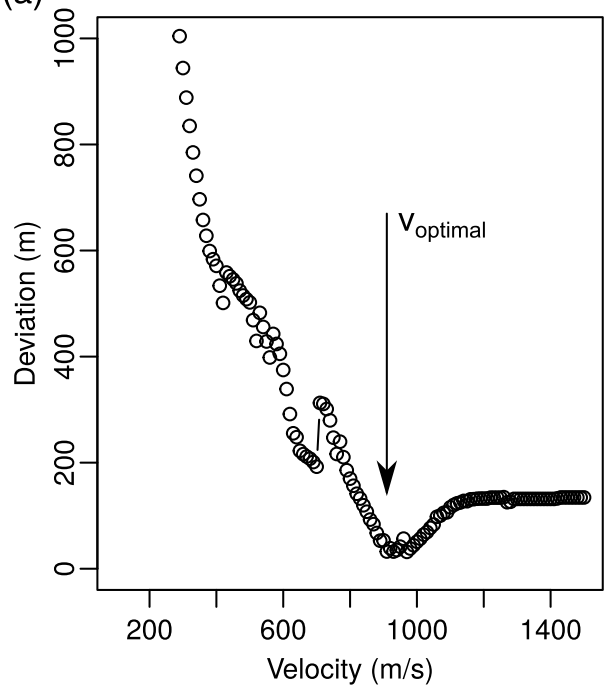

(b)

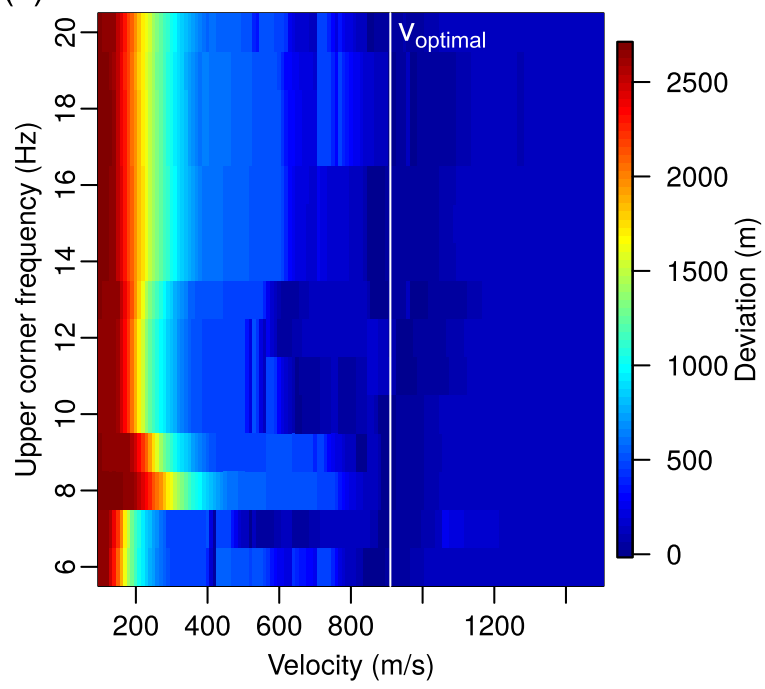

Figure 4. Estimate of apparent seismic wave velocity by minimization of model location deviations from empirically known location. (a) Deviation as function of wave velocity for 5-10 Hz filtered signals. (b) Deviation map resolving deviation as function of wave velocity and filter frequency width ( $5 \mathrm{~Hz}$ as fixed lower corner frequency). White vertical line depicts optimal velocity $\left(v_{\text {optimal }}=910 \mathrm{~m} / \mathrm{s}\right)$ from (a) to illustrate the general agreement of this optimal value also for other frequencies.

We use an event on 21 March 2017 at 04:38 UTC time to illustrate the insights from combining the seismic monitoring and UAV surveying (Figures $2 \mathrm{f}$ and $2 \mathrm{~g}$ ). This failure, located about $200 \mathrm{~m}$ south of station "Beloved Peregrine," generated a seismic signal with an emergent onset, a rise time of $1.5 \mathrm{~s}$, and a fall time of $7.3 \mathrm{~s}$ (see white signal time series on top of spectrograms in Figure 2f). Photographs taken by park authorities 3 days after the event confirmed it as a cliff failure involving around $800 \mathrm{~m}^{3}$ of material that fragmented during transport and covered the beach as a flow-like deposit, extending into the sea (Figure 2d). Our UAV-based change model, based on a survey in May 2017, shows a cliff failure with a volume of $920 \pm 50 \mathrm{~m}^{3}$, located at $32 \mathrm{~m}$ above sea level, and a corresponding deposit of $850 \pm 42 \mathrm{~m}^{3}$ (Figure $2 \mathrm{~g}$ ), not including material beneath the water level, thus rendering the mapped deposit volume a minimum estimate.

The optimal apparent seismic wave velocity for event location (Figure 4) yielded a consistent value of $910 \mathrm{~m} / \mathrm{s}$ regardless of the width of the filter window applied to the seismic data. For this seismic velocity, the location error was minimized at $37 \mathrm{~m}$. Assuming constant conditions, we used this velocity value for location of all other detected failures.

Based on UAV-derived 3-D models, we measured compound failure volumes between 1.10 and $4,985 \mathrm{~m}^{3}$ $\left(20.0_{-13.6}^{+35.8} \mathrm{~m}^{3}\right)$. The cumulative detected failure volumes for the seasons with vegetation activity (May-October) were 236 and $389 \mathrm{~m}^{3}$ in 2017 and 2018, respectively. For the nonvegetative seasons, the cumulative volumes were 1,029 $\mathrm{m}^{3}$ (2017, March-April), 14,248 $\mathrm{m}^{3}$ (2018, November-April), and $471 \mathrm{~m}^{3}$ (2019, November-April, cf. Figure $1 \mathrm{~g}$ for a summary). In many cases the UAV imagery showed that new cliff base deposits were amalgams of multiple cliff failures (Figure 2b). Failures initiated at heights of $29.0_{-16.0}^{+10.5} \mathrm{~m}$ asl and $24.0_{-9.0}^{+3.7} \mathrm{~m}$ below the cliff top. Many failure scars and deposits were the result of multiple events. This prevented us from constraining the relationship between individual event seismic amplitudes and volumes, and precluded a robust volume-frequency analysis.

Screening for precursor activity during $60 \mathrm{~min}$ before the failures revealed random brief pulses of seismic activity at the closest station in a few instances (e.g., 9 April 2018 19:04, 10 March 2018 02:50, 9 March 2018 23:34, 15 February 2018 02:15, and 1 January 2018 02:17). We did not find a systematic increase in amplitude or decrease in recurrence time of these pulses toward the cliff failure.

\subsection{Trigger Time Lags and Activity Cycles}

We measured the time difference between the 81 recorded cliff failures and the preceding manifestation of a potential trigger and label this the trigger time lag. Freeze-thaw time lags were considered within a 72-hr window. The time lags of the 20 failures that occurred within this window peaked around $48 \mathrm{hr}$. Time lags 


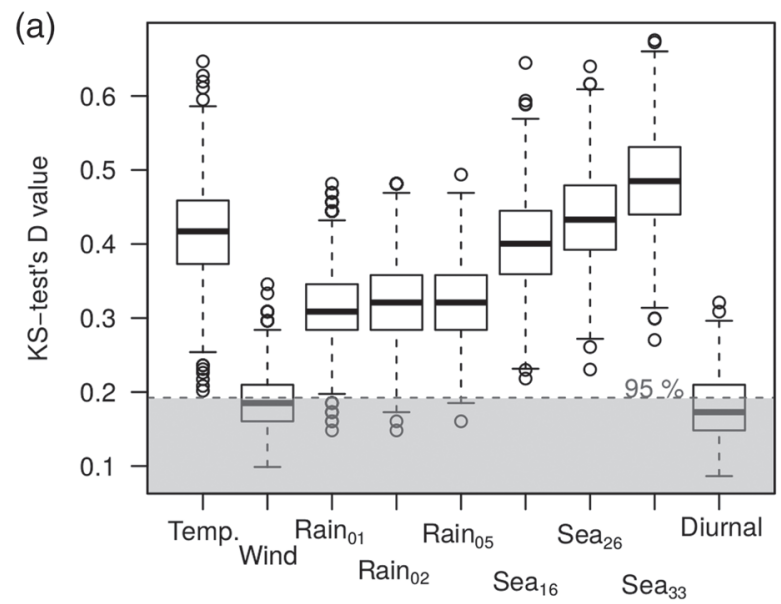

Trigger type

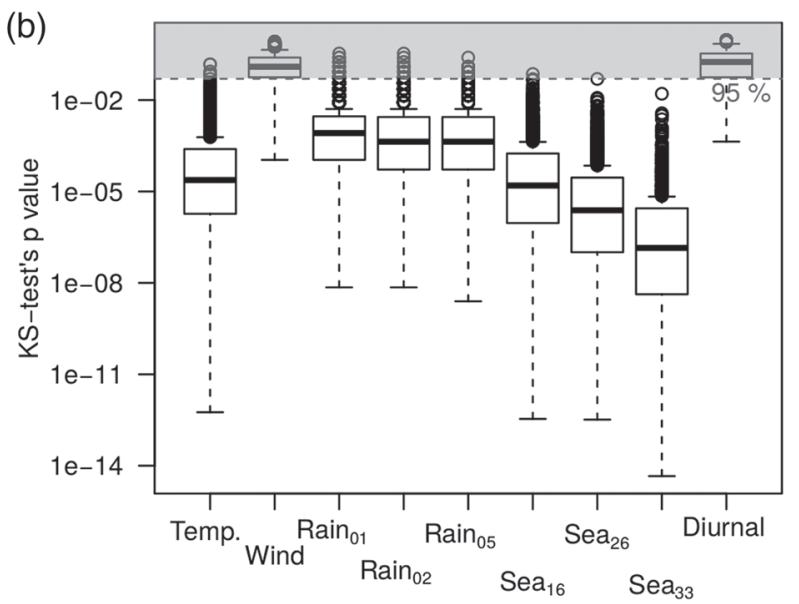

Trigger type

Figure 5. Statistical (Kolmogorov-Smirnov) significance tests for the triggers of cliff failures (null hypothesis: random occurrence). (a) $D$ values and (b) $p$ values for $95 \%$ significance thresholds indicated by horizontal dashed lines. Gray shaded areas depict insignificant cases. Triggers are listed along the $x$ axis, including freeze-thaw transitions (Temp.), high wind speeds (Wind), precipitation at three intensities (Rain ${ }_{01},{ }_{02}$, and ${ }_{05} \mathrm{~mm} / \mathrm{hr}$ ), sea levels (Sea ${ }_{16},{ }_{26},{ }_{33} \mathrm{~cm} \mathrm{above}$ average), and preference of failures at night versus day time (Diurnal).

for precipitation showed bimodal distributions for all three threshold values $(0.1,0.2$, and $0.5 \mathrm{~mm} / \mathrm{hr})$ at $0-3$ and 16-20 hr, for between 62 and 67 out of the 81 failures depending on the rainfall rate. There is also a very suppressed third mode between 30 and $40 \mathrm{hr}$. Time lags for wind showed a plateau between 1 and $10 \mathrm{hr}$ and secondary modes at $35-55 \mathrm{hr}$ for a total of 71 failures. Sea level time lags were $0-2 \mathrm{hr}$ for all three thresholds, applying to 17-30 failures. Sea level standard deviation within the 20-min moving window was $4.18_{-1.54}^{+3.01} \mathrm{~cm}$ (maximum $30.2 \mathrm{~cm}$ ). Time lag analysis showed that only $7\left(\mathrm{q}_{75}\right)$ to $15\left(\mathrm{q}_{95}\right)$ failures had sea level-related time lags within 0-2 hr during the 3-day period of interest. Except for wind, all time lag distributions were significantly different from random (i.e., Kolmogorov-Smirnov (KS) test $D$ values $>0.24$ and $p$ values $<0.01$; see Figure 5).

Failures showed a tendency to happen during night time hours. Fifty failures occurred between 8 p.m. and 8 a.m., and 31 between 8 a.m. and 8 p.m. (Figure $6 \mathrm{~b}$ ), but this variability is not significantly different from random $\left(D=0.17_{-0.02}^{+0.04}, p=0.18_{-0.12}^{+0.16}\right)$. A diurnal pattern was also observed in air humidity, ranging on average between $75 \%$ and $87 \%$ over a day-night cycle in summer $\left(D=0.38_{-0.04}^{+0.08}, p<0.07\right)$ and between $82 \%$ and $90 \%$ in winter $\left(D=0.46_{-0.04}^{+0.04}, p<0.002\right)$. During days with failures, air humidity was especially high, between $85 \%$ and $94 \%\left(D=0.38_{-0.04}^{+0.08}, p<0.07\right)$, with peak values preceding cliff failure by $1-2 \mathrm{hr}$.

At the monthly scale, failures occurred more frequently when the Moon was farther away from the cliff (Figure 6c; 65 vs. 16 with respect to the average lunar distance). The lunar distance ranges from 350,000 to $410,000 \mathrm{~km}$, a $14.4 \%$ difference. Spectral analysis revealed statistically significant periodicity modes between 25 and 29 days for lunar distance, precipitation, and cliff failures (Figure 6d). The systematic relationship with cliff failure was only violated during the days around the year end 2017/2018 (Figure 6c, Cluster c3 in Figure 1). That episode, with a total of 12 subsequent failures, seven of them at nearly the same location, was associated with persistent precipitation ( $31 \mathrm{~mm}$ in 7 days, compared to a 30-year monthly average of $46 \mathrm{~mm}$ ).

Detected failure occurrence as inferred from seismic and UAV data was highly seasonal (Figures $1 \mathrm{~b}$ and $1 \mathrm{~g}$ ) with most of the volume mobilized between November and April. In contrast, precipitation was stronger between May and October (331 mm vs. $250 \mathrm{~mm}$ ). A cyclic trend was also observed in the seismic velocity data (Figure 1f) with high dv/v values during May and October, decreasing with the onset of late autumn. However, this pattern was decoupled from the evolution of the groundwater level (Figure 1e).

Finally, during the instrumented period we have recorded the imprint of a comparatively wet year with $121 \%$ of the 30 -year average precipitation, including $126 \%$ for May to October 2017 , followed by a drier-than-average year with precipitation totalling $74 \%$ of the 30 -year average, including a summer season with only $51 \%$ of the average seasonal rainfall (Figure 1d). We have seismically detected 65 cliff failures during the winter season of the wet year, and only 11 failures in the winter season of the dry year. 
(a)

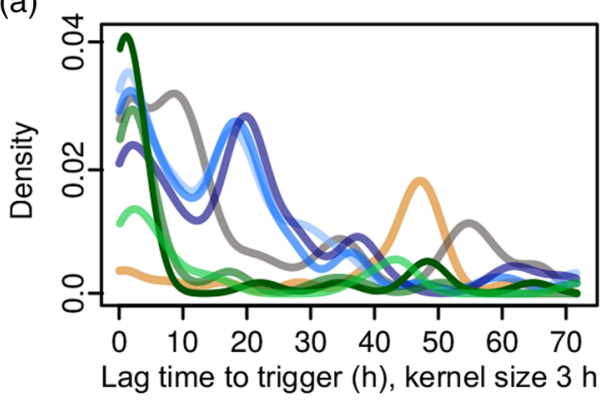

Lag time to trigger (h), kernel size $3 \mathrm{~h}$

Freeze-Thaw Rain $(\mathrm{mm} / \mathrm{h})$ Sea level $(\mathrm{cm})$

- (20)

$-0.1(67)$

$-+16(30)$

Wind (Bf 6)

$=0.2(64)$

$-+26(24)$
-

(b)

$-(71)$

$-0.5(62)$

$-+33(17)$

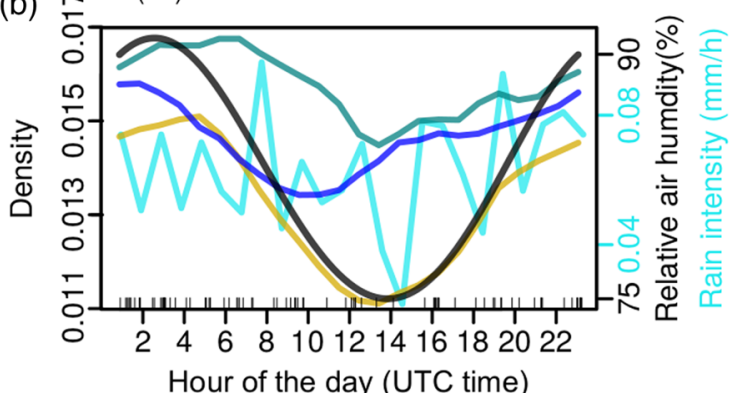

Hour of the day (UTC time)

- failures (3 h kernel) - Rel. hum. failure days

- Average rain intensity -Rel. hum. summer

(c)

-Rel. hum. winter

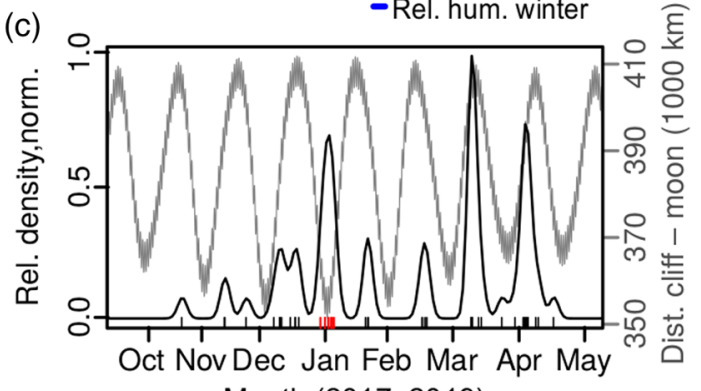

(d)

Month (2017-2019)

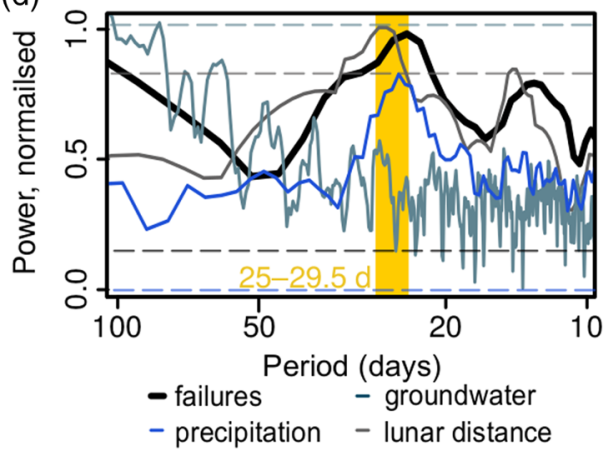

Figure 6. Drivers and triggers of cliff failures on Jasmund. (a) Kernel density estimates ( $72 \mathrm{hr}$ duration) of time lags between triggers and failures. Values in parentheses denote number of failures within $72 \mathrm{hr}$. (b) Diurnal failure activity density estimate (black line), relative air humidity, and average diurnal precipitation intensity. (c) Seasonal failure density estimates (period 2017-2019). Rugs along the $x$ axis denote individual failures (red rugs indicate anomalous failure phase around the year end 2018). Gray curve shows lunar distance, that is, distance between the gravity center of the Moon and the cliff area. (d) Spectra of cliff failures and potential drivers. Lunar distance, precipitation, and failures share a common periodicity window (orange polygon) at 25-29.5 days. Horizontal dashed lines depict significance thresholds for the spectra. 


\section{Discussion}

\subsection{Propagation and Spatial Properties of Cliff Failures}

The UAV-based failure heights $\left(20.0_{-13.6}^{+35.8} \mathrm{~m}^{3}\right.$, following a log-normal distribution, with six volumes between 1.0 and $3.7 \mathrm{~m}^{3}$ ) were in general well above the estimated minimum failure volume that can be detected seismically (about $4 \mathrm{~m}^{3}$ ). Any geometric bias in failure detection due to the seismic network layout was minimal for the central part of the cliff, where the distance to a set of three stations was less than $2 \mathrm{~km}$ throughout. Note, however, that this bias only potentially affects the event location, not the detection limit. The size of our catalogue was small compared to catalogues from other approaches (e.g., Lim et al., 2010; Vann Jones et al., 2015). Thus, our data did not allow for a meaningful evaluation of magnitude-frequency relationships or the role of small failures $\left(<4 \mathrm{~m}^{3}\right)$ in long-term cliff erosion, and we did not attempt a full erosional budget. However, the catalogue did permit the analysis of activity patterns along the entire cliff coast and an investigation of the kinetics of single failures, temporal clustering of cliff failures, and the links between failures and trigger mechanisms.

Recorded events had similar rise and fall times, durations, and frequency contents of seismic signals. Combined with the UAV-based locations at $29.0_{-16.0}^{+10.5} \mathrm{~m}$ above the cliff base and $24.0_{-9.0}^{+3.7} \mathrm{~m}$ below the cliff top (pointing at the midcliff area as preferred failure sites), this suggests that the failures had comparable detachment and displacement processes. We observed predominantly spindle shaped seismograms, which reflect the avalanching movement of fragmented chalk volumes that spread out at the cliff base. Many of the detected events were not intact block falls, which would produce single seismic pulses (Dietze, Turowski, et al., 2017; Hibert et al., 2011). These results were in agreement with observations of the example failure (Figure 2). This event generated a deposit with a volume of at least $850 \mathrm{~m}^{3}$, forming a radial sediment body that could be eroded and modified by waves immediately. The erosive action of the Baltic Sea is visible in Figure $2 \mathrm{~d}$, where the deposit feeds a plume of bright chalk material into suspension.

During the survey period, recorded activity was focused predominantly in the central cliff section, between stations "Beloved Peregrine" and "Shrapnel City," with only seven failures outside this area (Figure 1a). This activity pattern is reflected in the shape of the different cliff sections. Between the two central stations, the cliff is steepest $\left(46 \pm 16^{\circ}\right.$ average slope) and has the most overhanging facets. It is mostly devoid of vegetation and has waterfalls at the outlets of creeks. North and south of the two central stations, slopes are gentler, $38 \pm 13^{\circ}$ and $41 \pm 16^{\circ}$, respectively, and several channels have incised to sea level. This contrast suggests that activity segmentation manifests itself in the geomorphology, with failure-driven cliff retreat in the center of the Jasmund coast and diffusive or catchment-confined hillslope sediment transport to the north and south. The reason for this segmentation of cliff shaping process combination remains elusive from our study design (time scale of surveying, measurement parameters included). While spatial differences in meteorological conditions, marine effects, and landcover are unlikely to be significant, it may be the glacial thrusting dynamics that have generated an increased susceptibility of the central cliff section to water availability and flow below the surface.

\subsection{Triggers of Cliff Failures}

The seismic records were missing during the summer periods, but according to the UAV results, the total volumes of failures during summer were always lower than during winter periods. Without complete seismic information we cannot include the summer periods in our subsequent trigger analysis, which introduces a possible seasonal bias. However, the UAV change detection results showed similar detachment elevations and deposit shapes throughout summer and winter seasons. Thus, we infer that unrecorded summer failures should be comparable to those for which we have seismic data.

Cliff failures were significantly linked with precipitation in about half of the cases. Time lags show two clusters, at $0-3(n=19)$ and $16-20(n=20)$ hours (Figure 6a). This suggests that rain may impact cliff stability through two different mechanisms. We interpret the rapid response as the effect of rain directly onto the cliff, and the delayed response as the consequence of water flow toward the cliff face within the soil covering the chalk landscape at the cliff top. Typical hydraulic conductivity values for unfractured Rügen chalk, $k_{f} \sim 10^{-10} \mathrm{~m} / \mathrm{s}$ (Krienke \& Koepke, 2006), allow flow rates of only a few micrometers per day, whereas the higher conductivity of the cover material, $k_{f} \sim 10^{-4} \mathrm{~m} / \mathrm{s}$, theoretically permits water from up to $8.6 \mathrm{~m}$ hinterland to seep into the cliff face within a day. Note that seepage can have a longer range where preferential, lateral flow paths are present, for example, along fractures and discontinuities, or in sediment-filled hollows. 
We reject wind, sea level, waves, and freeze-thaw transitions as important triggers based on KS test results (Figure 5, distance values $D$ below and $p$ values above the $95 \%$ significance threshold levels) and a lack of plausible mechanisms for the measured time lags. Wind time lags plateau between 0 and $10 \mathrm{hr}$ (Figure 6a), and within this window, they are not distinct from random. We have not found a plausible mechanistic interpretation of this distribution, especially with failures predominantly occurring at $29.0_{-16.0}^{+10.5} \mathrm{~m}$ above the beach and $24.0_{-9.0}^{+3.7} \mathrm{~m}$ below the cliff top, and thus outside the range of processes at the cliff toe or the tree covered cliff top. Sea level time lags of $0-3 \mathrm{hr}$ (for 17-30 out of 81 failures) are an effect of the seasonally changing sea level ( $514 \mathrm{~cm}$ in winter versus $502 \mathrm{~cm}$ in summer), which results in winter cliff failures mapping onto higher sea levels. Wave amplitude variability (running window standard deviation of sea level) of a few centimeters, with a maximum of $30.2 \mathrm{~cm}$, is 1 order of magnitude smaller than the height of the beach ramp. In this configuration, direct impact of waves on the base of the cliff is rare, and indirect impact will be damped by the coarse, unconsolidated beach sediment. Moreover, the persistence of fine-grained deposits at the cliff base (Cook \& Dietze, 2019) throughout multiple UAV surveys (i.e., throughout several months) further indicates that waves have rarely impacted the base of the cliff during our study period. It is likely that waves have not acted as triggers of cliff failure over the monitoring interval. However, waves have played an important role in episodically removing the loose failure material from the base of the cliff (e.g., Rosser et al., 2013). Tides of $\sim 15 \mathrm{~cm}$ appear to be irrelevant given that the ramp of the shore platform has a height range of 1-2 m. In addition, most of the failures occur at $29.0_{-16.0}^{+10.5}-\mathrm{m}$ height above the beach, without indications of undermining at the base. Thus, we reject high sea levels and tides as trigger mechanisms for the documented failures. Freeze-thaw time lags of about 2 days (Figure 6a) render this mechanism an unlikely trigger because heat dissipation probably happens within hours rather than days (Dietze, Mohadjer, et al., 2017). A further potential cause for failures could be the occurrence of a previous failure, destabilizing the cliff's stress field (e.g., Rosser et al., 2007). Indeed, we find that in $26 \%$ of cases, another failure happened within $24 \mathrm{hr}$ after a preceding one at or near the same location. However, the spatial confidence of the seismic location approach is too low to pursue this in the context of our network geometry and station spacing. Future studies engaging with this particular topic require denser instrument networks and higher sampling rates. Finally, note that there may be failures without any detectable (or detected) trigger mechanism (e.g., Stock et al., 2013), a phenomenon we also see in our trigger results, specifically in the number of events within the trigger lag time analysis window (numbers in parentheses in Figure 6a), which is always smaller than the size of the failure catalogue.

Precipitation is a typical cause of rock slope failure, but from our data we see a further aspect of water in the environment. Another (though not statistically significant) trend is that cliff failures occurred more frequently during the night (Figure 6b). Rain has a mostly uniform distribution throughout the day (Figure 6b) so cannot explain this diurnal pattern of failures. During days with failures, recorded during the winter season, relative air humidity was systematically higher than during other winter days and especially compared to summer season days (Figure 6b). Most importantly, cliff failure activity followed the daily relative humidity cycle with a time lag of $1-2 \mathrm{hr}$. Therefore, we propose that relative humidity may contribute to cliff activity at this time scale, even in the absence of rain. During the cooling hours at the end of the day, increased humidity and decreasing air temperature can lead to crossing of the dew point. Rates of dew formation on various surfaces range between $10^{-2}$ and $10^{-1} \mathrm{~mm} / \mathrm{hr}$ (Garratt \& Segal, 1988), with controls exerted by meteorological conditions and surface properties. These dew formation rates can cause cumulative overnight water deposition at the same order as precipitation thresholds $(0.1,0.2,0.5 \mathrm{~mm} / \mathrm{hr})$ used in our trigger analysis. This water can migrate quickly into the fractured chalk at the cliff face and increase the water content of the material, possibly causing rheological changes.

We propose that the cliff failures observed during this study occurred primarily due to wetting of the fractured chalk. This wetting can be due to rain directly onto the cliff, subsurface flow toward the cliff, or condensation of atmospheric water vapor at the cliff surface. Regardless of the pathway, increased water content can result in a sharp transition in rheological behavior of the cliff-forming material, from rigid to liquid. Increased water content contributes to failures by increased loading and shear strength reduction, which adds to the instantaneous effect of the material state transition at the cliff face upon sufficient wetting.

The absence of wave forcing in our study area allowed us to specifically study the role of terrestrial drivers and triggers, at much greater detail and resolution than would be possible in regions where marine processes play a significant role, as well. The proposed moisture-driven mechanism requires a rheological setting in which seasonal and shorter-term water content changes can cause material state transitions. Thus, while 
coastal chalk cliffs are most likely prone to this effect, and cliffs with sandy or weakly consolidated material may undergo similar processes, more resistant lithologies such as limestone or crystalline rock would be less prone to moisture-driven failures. Since the chalk properties in other coastal cliff landscapes (e.g., Duperret et al., 2005) do not differ substantially from the properties of our study site, moisture-driven failure activity might be a generic mechanism in such lithologies. However, unless studies at other sites also utilize the information that can be provided by high-resolution joint seismic and remote sensing surveying, the relative contribution of cliff internal versus wave-driven failure initiation remains obscured.

\subsection{Cliff Activity at the Lunar Cycle}

The overlapping spectral peaks of cliff activity and lunar distance were unexpected. At a first glance, one would expect lunar distance (JPL, 2019) to affect the net local gravitational force at the Earth's surface, imposing dilation of bedrock, changes in pore space and decreasing groundwater potential via tidal stress (e.g., Inkenbrandt et al., 2005). However, effects on the net gravitational force are negligible: a $10^{-7}$ decrease of Earth's gravitational pull when the moon is closest to the study area. Similarly, tides in the Baltic sea are small, and sea level does not appear to be a direct cause of detected cliff failures. An influence of the Moon on groundwater has been reported, although predominantly on the diurnal and semidiurnal scale (Briciu, 2014). However, groundwater on Jasmund did not show any significant lunar periodicity (Figure 6d).

Perhaps more relevant, Cerveny et al. (2010) found a robust lunar signal in river discharge across the United States, which they attributed to a precipitation cycle synchronized with the lunar month. Such synchronous effects were also identified in other settings around the globe (Adderley \& Brown, 1962; Bradley et al., 1962; Lethbridge, 1990; Roy, 2006). Quoting Cerveny et al. (2010), it emerges that "as a potential cause to these previous findings of tidal forcing's influence on precipitation and thunderstorms, past climatological and astronomical research has proposed that the lunar synodic cycle may be linked to (a) lunar distortion of the Earth's magnetic tail [Lethbridge, 1970, 1990], (b) the occurrence of cosmic rays [Markson, 1981], and (c) variations in meteoric dust [Adderley and Brown, 1962] acting as condensation nuclei, among other explanations." This relationship is in line with our data showing agreement of significant spectral peaks of precipitation, lunar distance, and cliff failures (Figure 6d). Thus, based on these findings, we propose that lunar cyclicity may affect cliff failures indirectly, through the mediating role of precipitation. Obviously, longer time series with more precisely dated failures are needed to better constrain this proposed relationship.

\subsection{Biotic Cliff Preconditioning}

There is an important seasonal effect that preconditions the Jasmund cliff system for failure on shorter, lunar (Figure 6c), and diurnal (Figures 6a-6b) time scales. Although we lacked seismic evidence of cliff failures during the summer periods when no sensors were operational, we recorded only minor released volumes based on the UAV data ( 236 and $389 \mathrm{~m}^{3}$, respectively), indicating that the summer periods were likely less active than the November-May windows. We attribute this seasonal pattern to water uptake by the dense beech forest covering the cliff hinterland. On Jasmund, the vegetative season typically starts in early May and ends in October-November. During this season, water uptake by trees leads to progressive drying of the subsurface beyond the recharge capacity of summer rain. Beech trees can transpire hundreds of liters of soil water per day (Střelcová et al., 2002), leading to prolonged negative water potentials during the vegetative season. In a beech dominated natural forest in central Europe (Střelcová et al., 2002), soil water potential throughout the first $70 \mathrm{~cm}$ graded from -80 to $-700 \mathrm{hPa}$ between late spring and autumn. This prevents major lateral soil water movements during the vegetative season. Moreover, leaves contribute about 30\% to evaporation of rain water before it reaches the ground (interception loss), further contributing to systematically drier soil conditions between spring and autumn (Friesen \& Van Stan II, 2019). During vegetation dormancy, from November to May, water uptake by roots and interception loss is limited, and rain storms can optimally recharge the antecedent soil moisture budget (SI Figure S2). Hence, we infer that there is a vegetation control on cliff stability on Jasmund, expressed on the seasonal scale, through the regulation of antecedent soil moisture.

The seasonal antecedent soil moisture cycle is supported by our data on near-surface seismic wave velocities (Figure 1f). Since the dv/v values result from an inversion process that finds those values within a sliding time window that can best explain the change in the seismic properties, there is no uncertainty estimate associated with the results. However, overall similar trends in the dv/v time series of two stations standing 
more than a kilometer apart from each other indicates a coherent forcing mechanism. Estimated dv/v values of our two central seismic stations were high by the end of the vegetative season and started to decline around November, before rising again in late spring. We attribute this to drying of the near-surface substrate in summer, and wetting in winter. Relative wave velocity increases as the ground material becomes more rigid (or when its temperature increases Clements \& Denolle, 2018) and vice versa. In the case of the chalk from our study region, rigidity is strongly controlled by moisture content, and less so by temperature changes, especially at several decimeters depth and under a dense beech canopy. These $\mathrm{dv} / \mathrm{v}$ trends were not consistent with the groundwater levels, which fluctuated by about $1 \mathrm{~m}$ at a depth of about $15 \mathrm{~m}$ below the surface, suggesting that our wave velocity monitoring was mostly sensitive to near-surface soil moisture content. Moreover, in the long term, groundwater levels (see the SI for details) vary not only at the annual scale (about 0.2 - to $0.3-\mathrm{m}$ amplitude of change) but more drastically at the multiyear scale (up to $1.5-\mathrm{m}$ amplitude of change during the last decade), masking annual effects completely. Our instrumented period captures one such large scale effect: the above average wet year of 2017 resulted in a groundwater high stand while the above average dry year of 2018 caused a local low stand of groundwater (Figure 1e) independent of smaller amplitude changes at the seasonal scale.

\subsection{Multiyear Scale of Cliff Activity}

We identified a legacy of climatic boundary conditions, expressed in a large number and volume of cliff failures in winter $2017 / 2018$ after a wet summer with $126 \%$ of average seasonal precipitation (117\% in the subsequent winter), and a smaller failure number and volume in winter 2018/2019 after a dry summer with only $51 \%$ ( $97 \%$ in the subsequent winter) of the average precipitation. Whether the effect is driven by the summer period, with more intense deviations from the average patterns, or the winter period with less (2018) to negligible (2019) deviations, remains elusive from our data. However, in light of the above explained effect that vegetation causes overall dry soil conditions during summer and allows the restoration of sufficient moisture conditions predominantly during winter dormancy, it appears more likely that it is the summer period that sets the boundary conditions for the subsequent winter period of cliff failure density.

Future climate projections for Jasmund include generally drier conditions and more variable precipitation events (Frei et al., 2006; Umweltbundesamt, 2015). With sustained moisture in the cliff and frequent precipitation being the dominant driver and trigger for failures identified in our study, the chalk cliffs may experience fewer failures as the decreasing lateral water input fails to precondition the system to a state where rain and relative air humidity can trigger failures in the volume range witnessed during our study period. On the multiyear turn, this may result in a decreasing sediment supply via failures to the cliff base and beach environment for uptake by waves agitating those deposits (cf. Figures 2b and 2d Stephensen, 2014). As a consequence, the erosive action of waves would extract more and more fine material from the beach instead, until the currently $2 \mathrm{~m}$ high ramp has become sufficiently lower and waves would be able to affect the cliff base directly. Ultimately, the coast cliffs may become increasingly prone to wave action with possible undercutting, as the absence of a sediment apron and the proximity to breaking waves makes them more prone to net basal erosion. This may eventually lead to less frequent but more catastrophic failures with significantly larger volumes, as failures would not initiate at $29.0_{-16.0}^{+10.5}-\mathrm{m}$ height and due to local destabilisation caused by a moisture-driven chalk state transition, but at the cliff base and due to destabilising process that penetrates deeper into the chalk material. Thus, although under generally drier conditions the rigidity of the cliff would increase, the failure volumes would increase, as well (see, e.g., discussion by Dussauge et al., 2003). Unlike sandy beaches, cliffs are not able to recover after erosive events by aggradation of new material from other than cliff derived sources (Stephensen, 2014). Thus, there is no adjusting response mechanism in such an erosive system, which makes estimating the consequences of climate change for cliff coasts even more important.

\section{Conclusions}

We have used a combined seismic and UAV approach to gain new insight to dynamics and triggers of coastal cliff activity, allowing the exploration of geomorphic relationships across a larger spatial and temporal range than would be possible with other existing techniques. This has revealed that, in the absence of strong tidal and wave forcing as direct triggers of failures, patterns, and frequencies of cliff failures along the chalk coast of Jasmund, Germany, are affected by the presence of water in the cliff on a range of time scales. Water controls the rigidity of the material and causes a state transition, from solid toward liquid. This gives rise to 
distinct cycles of cliff failure at annual, seasonal, diurnal, and possibly lunar time scales. Climatic effects set the baseline for failure frequency, soil moisture uptake by trees suppresses failures in the vegetation period, precipitation causes failures by direct rain onto and groundwater flow toward the cliff, and higher atmospheric moisture levels may promote failures during the night. Failure deposits are typically amalgams and our seismic data reveals their formation from clusters of geomorphic activity rather than from single failures. Under increasingly drier climate conditions, the cliff may grade into a (different) transient, characterized by less frequent small failures due to insufficient moisture preconditions, which in turn may prepare the cliff for more large events driven by erosion at the cliff base.

\section{Data Availability Statement}

The underlying data sets are provided under DOI 10.17605/OSF.IO/FV64X (https://osf.io/fv64x/). Seismic data are available via GEOFON data services.

\section{Acknowledgments}

This research was made possible by the Helmholtz Impulse and Network Fund. The analysis scripts are provided in the supporting information. We thank Christopher Roettig and Sascha Meszner for the enlightening discussion on lunar influence on cliff activity and Björn Piltz for his input on lunar orbital parameters, as well as Theresa Blume for the suggested soil moisture input. An anonymous tractor driver is thanked for saving the Spring 2018 survey mission. We thank the three reviewers and the Editor for the thoughtful and constructive input. Open access funding enabled and organized by Projekt DEAL.

\section{References}

Adderley, E. E., \& Brown, E. G. (1962). Lunar component in precipitation data. Science, 749-750, 137. https://doi.org/10.1126/science. 137.3532.749

Allen, R. (1982). Automatic phase pickers: Their present use and future prospects. Bulletin of the Seismological Society of America, 72 , S225-S242.

Bradley, D. A., Woodbury, M. A., \& Brier, G. W. (1962). Lunar synodical and widespread precipitation. Science, 748-749, 137. https://doi. org/10.1126/science.137.3532.748

Briciu, A.-E. (2014). Wavelet analysis of lunar semidiurnal tidal influence on selected inland rivers across the globe. Scientific Reports, 4 , 4193.

Burtin, A., Hovius, N., Milodowski, D. T., Chen, Y.-G., Wu, Y.-M., Lin, C.-W., et al. (2013). Continuous catchment-scale monitoring of geomorphic processes with a 2-D seismological array. Journal of Geophysical Research: Earth Surface, 118, 1956-1974. https://doi.org/ 10.1002/jgrf.20137

Burtin, A., Hovius, N., \& Turowski, J. M. (2016). Seismic monitoring of torrential and fluvial processes. Earth Surface Dynamics, 4, 285-307. https://doi.org/10.5194/esurf-4-285-2016

Cerveny, R. S., Svoma, B. M., \& Vose, R. S. (2010). Lunar tidal influence on inland river streamflow across the conterminous United States. Geophysical Research Letters, 37, L22406. https://doi.org/10.1029/2010GL045564

Clements, T., \& Denolle, M. A. (2018). Tracking groundwater levels using the ambient seismic field. Geophysical Research Letters, 45 , 6459-6465. https://doi.org/10.1029/2018GL077706

Collins, B. D., \& Sitar, N. (2008). Processes of coastal bluff erosion in weakly lithified sands, Pacifica, California, USA. Geomorphology, 97, 483-501. https://doi.org/10.1016/j.geomorph.2007.09.004

Collins, B. D., \& Stock, G. M. (2016). Rockfall triggering by cyclic thermal stressing of exfoliation fractures. Nature Geoscience, 9, 395-400.

Cook, K. L., \& Dietze, M. (2019). Short communication: A simple workflow for robust low-cost UAV-derived change detection without ground control points. Earth Surface Dynamics, 7(4), 1009-1017. https://doi.org/10.5194/esurf-7-1009-2019

DWD (2019). Climate data centre. https://www.dwd.de/EN/climate_environment/cdc/cdc_node.html

Dietze, M. (2018a). "eseis"-An R software toolbox for environmental seismology. v. 0.4.0. GFZ Data services.

Dietze, M. (2018b). The R package "eseis" a software toolbox for environmental seismology. Earth Surface Dynamics, 6, 669-686. https:// doi.org/10.5194/esurf-6-669-2018

Dietze, M., Kreutzer, S., Burow, C., Fuchs, M. C., Fischer, M., \& Schmidt, C. (2016). The abanico plot: Visualising chronometric data with individual standard errors. Quaternary Geochronology, 31, 12-18.

Dietze, M., Mohadjer, S., Turowski, J. M., Ehlers, T. A., \& Hovius, N. (2017). Validity, precision and limitations of seismic rockfall monitoring. Earth Surface Dynamics, 2017, 1-23. https://doi.org/10.5194/esurf-2017-12

Dietze, M., Turowski, J. M., Cook, K. L., \& Hovius, N. (2017). Spatiotemporal patterns, triggers and anatomies of seismically detected rockfalls. Earth Surface Dynamics, 5(4), 757-779. https://doi.org/10.5194/esurf-5-757-2017

Duperret, A., Taibi, S., Mortimore, R. N., \& Daigneault, M. (2005). Effect of groundwater and sea cycles on the strength of chalk rock from unstable coastal cliffs of NW France. Engineering Geology, 78, 321-343. https://doi.org/10.1016/j.enggeo.2005.01.004

Dussauge, C., Grasso, J.-R., \& Helmstetter, A. (2003). Statistical analysis of rockfall volume distributions: Implications for rockfall dynamics. Journal of Geophysical Research, 108(B6), 2286. https://doi.org/10.1029/2001JB000650

Frei, C., Schöll, R., Fukutome, S., Schmidli, J., \& Vidale, P. L. (2006). Future change of precipitation extremes in Europe: Intercomparison of scenarios from regional climate models. Journal of Geophysical Research, 111, D06105. https://doi.org/10.1029/2005JD005965

Friesen, J., \& Van Stan II, J. T. (2019). Early European observations of precipitation partitioning by vegetation: A synthesis and evaluation of 19th century findings. Geosciences, 9, 1-20. https://doi.org/10.3390/geosciences 9100423

GPL (2019). Cloudcompare, v. 2.10.1.

Garratt, J. R., \& Segal, M. (1988). On the contribution of atmospheric moisture to dew formation. Boundary-Layer Meteorology, 45, 209-236. https://doi.org/10.1007/BF01066671

Gehrmann, A. (2018). The multi-stage structural development of the Upper Weichselian Jasmund Glacitectonic Complex (Rügen, NE Germany) (Ph.D. Thesis), University of Greifswald.

Helmstetter, A., \& Garambois, S. (2010). Seismic monitoring of Sechilienne rockslide (French Alps): Analysis of seismic signals and their correlation with rainfalls. Journal of Geophysical Research, 115, F03016. https://doi.org/10.1029/2009JF001532

Hibert, C., Mangeney, A., Grandjean, G., Baillard, C., Rivet, D., Shapiro, N. M., et al. (2014). Automated identification, location, and volume estimation of rockfalls at Piton de la Fournaise volcano. Journal of Geophysical Research, 119, 1082-1105. https://doi.org/10. 1002/2013JF002970

Hibert, C., Mangeney, A., Grandjean, G., \& Shapiro, N. M. (2011). Slope instabilities in Dolomieu crater, Reunion Island: From seismic signals to rockfall characteristics. Journal of Geophysical Research, 116, F04032. https://doi.org/10.1029/2011JF002038 
Holmes, T. R. H., Owe, M., De Jeu, R. A. M., \& Kooi, H. (2008). Estimating the soil temperature profile from a single depth observation: A simple empirical heatflow solution. Water Resources Research, 44, W02412. https://doi.org/10.1029/2007WR005994

IZW (2003). Die Küste. https://izw.baw.de/die-kueste/0/k066102.pdf

Inkenbrandt, P. C., Doss, P. K., Pickett, T. J., \& Brown, R. J. (2005). Barometric and Earth-tide induced water-level changes in the Inglefield sandstone in southwestern Indiana. Proceedings of the Indiana Academy of Science, 114, 1-8.

JPL (2019). https://ssd.jpl.nasa.gov/horizons.cgi

Kennedy, D. M., Coombes, M. A., \& Mottershead, D. N. (2017). The temporal and spatial scales of rocky coast geomorphology: A commentary. Earth Surface Processes and Landforms, 42, 1597-1600. https://doi.org/10.1002/esp.4150

Kogure, T., Aoki, H., Maekado, A., Hirose, T., \& Matsukura, Y. (2006). Effect of the development of notches and tension cracks on instability of limestone coastal cliffs in the Ryukyus, Japan. Geomorphology, 80, 236-244. https://doi.org/10.1007/BF01066671

Krienke, K., \& Koepke, C. (2006). Landslides at the sea cliffs of the Isle of Rügen (northeast germany) during the winter of 2004/05-Geology and soil mechanics. Zeitschrift für geologische Wissenschaften, 34, 105-113.

LUNG (2019). https://www.lung.mv-regierung.de/insite/cms/umwelt/geologie/rohstoffgeologie/rohstoffgeologie_kreidekalk.htm

Lague, B. N., \& Leroux, J. (2013). Accurate 3D comparison of complex topography with terrestrial laser scanner: Application to the Rangitikei Canyon (NZ). ISPRS Journal of Photogrammetry and Remote Sensing, 82, 10-26. https://doi.org/10.1016/j.isprsjprs.2013.04. 009

Larose, E., Carrire, S., Voisin, C., Bottelin, P., Baillet, L., Guguen, P., et al. (2015). Environmental seismology: What can we learn on Earth surface processes with ambient noise? Journal of Applied Geophysics, 116, 62-74. https://doi.org/10.1016/j.jappgeo.2015.02.001

Lethbridge, M. D. (1990). Thunderstorms, cosmic rays, and solar-lunar influences. Journal of Geophysical Research, 95(D9), 13,645-13,649. https://doi.org/10.1029/JD095iD09p13645

Letortu, P., Costa, S., Cador, J. M., Coinaud, C., \& Cantat, O. (2015). Statistical and empirical analyses of the triggers of coastal chalk cliff failure. Earth Surface Processes and Landforms, 40, 1371-1386. https://doi.org/10.1002/esp.3741

Lim, M., Rosser, N. J., Allison, R. J., \& Petley, D. N. (2010). Erosional processes in the hard rock coastal cliffs of Staithes, North Yorkshire. Geomorphology, 114, 12-21.

Menatschi, L., Vousdoukas, M. I., Pekel, J.-F., Voukouvalas, E., \& Feyen, L. (2018). Global long-term observations of coastal erosion and accretion. Scientific Reports, $8,12,876$.

Meng, H., \& Ben-Zion, Y. (2018). Characteristics of airplanes and helicopters recorded by a dense seismic array near Anza California. Journal of Geophysical Research: Solid Earth, 123, 4783-4797. https://doi.org/10.1029/2017JB015240

Obst, K., \& Schütze, K. (2005). Analysis of cliff slides at the steep coast of Jasmund, Rügen in 2005. Zeitschrift für geologische Wissenschaften, 34, 11-37.

Rosser, N. J., Brain, M. J., Petley, D. N., Lim, M., \& Norman, E. C. (2013). Coastline retreat via progressive failure of rocky coastal cliffs. Geology, 41(8), 939-942.

Rosser, N. J., Lim, M., Petley, D., Dunning, S., \& Allison, R. (2007). Patterns of precursory rockfall prior to slope failure. Journal of Geophysical Research, 112, F04012. https://doi.org/10.1029/2006JF000642

Roy, S. S. (2006). Impact of lunar cycle on the precipitation in India. Geophysical Research Letters, 33, L01707. https://doi.org/10.1029/ 2005GL024771

STALUVP (2019). Groundwater log time series, Buddenhagen, Rügen.

Sens-Schönfelder, C. (2014). Monitoring and Imaging based on Interferometric concepts package. https://github.com/miic-sw/miic

Sens-Schönfelder, C., \& Wegler, U. (2006). Passive image interferometry and seasonal variations of seismic velocities at Merapi volcano, Indonesia. Geophysical Research Letters, 33, L21302. https://doi.org/10.1029/2006GL027797

Snieder, R. (2004). Extracting the Green's function from the correlation of coda waves: A derivation based on stationary phase. Physical Review E, 69, 046,610. https://doi.org/10.1103/PhysRevE.69.046610

Stř̌elcová, K., Matejka, F., \& Mindáš, J. (2002). Estimation of beech tree transpiration in relation to their social status in forest stand. Journal of Forest Science, 48, 130-140.

Stephensen, W. (2014). Rock coasts (first edition). In D. Masselink \& R. Gehrels (Eds.), Coastal environments and global change (pp. 256-379). John Wiley \& Sons.

Stock, G. M., Collins, B. D., Santaniello, D. J., Zimmer, V. L., Wieczorek, G. F., \& Snyder, J. B. (2013). Historical rock falls in Yosemite National Park. U.S. Geological Survey Data Series 746, 746, 17.

Umweltbundesamt (2015). Germany's vulnerability to climate change. https://www.umweltbundesamt.de/sites/default/files/medien/ 378/publikationen/climate_change_24_2015_summary_vulnerabilitaet_deutschlands_gegenueber_dem_klimawandel_2.pdf

Vann Jones, V. E., Rosser, N. J., Brain, M. J., \& Petley, D. N. (2015). Quantifying the environmental controls on erosion of a hard rock cliff. Marine Geology, 363, 230-242. https://doi.org/10.1016/j.margeo.2014.12.008

Voake, T., Nermoen, A., Ravns, C., Korsnes, R. I., \& Fabricius, I. L. (2019). Influence of temperature cycling and pore fluid on tensile strength of chalk. Journal of Rock Mechanics and Geotechnical Engineering, 11(2), 277-288. https://doi.org/10.1016/j.jrmge.2018.12.004 WSV (2019). http://www.pegelonline.wsv.de

Wieczorek, G. F. (1996). Landslide triggering mechanisms. In A. K. Turner, \& R. L. Schuster (Eds.), Landslides-Investigation and mitigation (pp. 76-90). Washington DC: Transportation Research Board, National Research Council, National Academy Press.

Williams, D. (2016). Chapter 37-Tailings storage facilities (Second Edition). In M. D. Adams (Ed.), Gold ore processing (pp. 663-676). Elsevier.

Young, A. P., \& Carilli, J. E. (2019). Global distribution of coastal cliffs. Earth Surface Processes and Landforms, 44, $1309-1316$. 